\title{
Picking a tree: habitat use by the tree agama, Acanthocercus atricollis atricollis, in South Africa
}

\author{
Leeann T. Reaney \& Martin J. Whiting* \\ Communication and Behaviour Research Group, School of Animal, Plant and Environmental Sciences, \\ University of the Witwatersrand, Private Bag 3, WITS, 2050 South Africa \\ Received 15 February 2002. Accepted 24 October 2002
}

\begin{abstract}
We studied tree agama (Acanthocercus a. atricollis) habitat use in the Magaliesberg mountain range in northern South Africa using sightings of marked individuals, and in a few cases, radio-telemetry. Acanthocercus a. atricollis preferentially selected thorn trees (46\%; Acacia karroo), followed by common sugarbush (10\%; Protea caffra) and dead trees (9\%). The type of tree selected was unrelated to lizard age class or sex. Multivariate analysis failed to show any age class or sex effects for specific tree physical characteristics, but did reveal a preference for trees with greater diameter, canopy cover and incidence of parasitic plants. We suggest that more 'complex' trees may enhance crypsis, facilitate escape from predation, or provide a foraging advantage. Acanthocercus a. atricollis selected night-time perches higher than those used during the day, possibly further offsetting predation risk.
\end{abstract}

Key words: tree selection, age-sex differences, nocturnal retreat sites, lizard, reptile.

\section{INTRODUCTION}

Habitat selection by animals has been defined as the active choice of an area from a range of alternatives in the absence of constraints (Partridge 1978). In reality, no area is free of constraints and habitat selection depends on the physical structure of the environment, the physiology of the animal, food availability and protection from predators (Ward \& Lubin, 1993). There are numerous studies on habitat selection of arboreal and semi-arboreal lizards, mostly dealing with the polychrotid genus Anolis (e.g. Rand 1964; Andrews 1971; Vitt et al. 1981). For arboreal lizards, tree structure is of obvious importance because trees provide foraging sites, nest sites, and refuges from predators and trees that have greater surface area and complexity are often more favourable (Cooper 1993). Retreat sites with suitable thermal conditions are also crucial for ectotherms as behavioural and physiological processes are strongly dependent on temperature (Huey 1982).

Habitat selection may also involve differences in sexual or ontogenetic responses to the physical environment (Heatwole 1977). Differences in body size have been shown to influence interspecific habitat use (Vitt et al. 1981) and should similarly influence different size classes within the same species (Jenssen et al. 1998). Often, differences in foraging behaviour (Bartosiewicz 1987) and predation risk (Shine 1989) cause males,

*Author for correspondence. E-mail: martin@gecko.biol.wits.ac.za females and juveniles to use different habitats. Competition avoidance may be another cause of intraspecific habitat segregation when individuals are competing for similar sized prey and taxa (Jenssen et al. 1998). Little data exists on habitat use in southern African lizards (but see Pianka 1986). Such data are important for comparative purposes and for understanding life history patterns. Furthermore, tree harvesting is increasingly placing pressure on the environment and baseline data on arboreal species dependent on trees may be important for future conservation plans.

The objective of this study was to determine habitat selection in the tree agama (Acanthocercusa. atricollis). Tree agamas occur throughout Africa, from Ethiopia in the north to coastal KwaZuluNatal, South Africa in the south. Acanthocercus a. atricollis are large $(120-150 \mathrm{~mm}$ snout-vent length), diurnal, arboreal lizards that are sexually dimorphic in size and colouration. Mature males are larger than females and have a bright blue head and throat and a broad yellow-green vertebral stripe, while females remain olive-coloured with black marbling (Branch 1998). They are ambush foragers, spend most of their time foraging in trees, and show no sexual differences in diet or foraging behaviour (Reaney \& Whiting 2002). We set out to determine 1) if $A$. a. atricollis select trees nonrandomly; 2) the physical attributes of trees they use; 3 ) if there are sexual and age/sizerelated differences in habitat use; and 4) what nocturnal retreat sites they use. 


\section{MATERIALS \& METHODS}

\section{Study area}

Field observations were conducted at Mountain Sanctuary Park, Magaliesburg, North West Province $\left(25^{\circ} 50^{\prime} \mathrm{S}, 27^{\circ} 28^{\prime} \mathrm{E}\right)$, South Africa during the 2000 breeding season (September-November; wet season). The mean ambient temperature in the area for the last 30 years (1960-1990) was $18.7^{\circ} \mathrm{C}$ (15.5 range; $\left.10.9-26.5^{\circ} \mathrm{C}\right)$, while annual rainfall averaged $650 \mathrm{~mm}$. Since lizard activity levels are typically higher during the breeding season, there may be a degree of seasonal bias in habitat use. The study area was situated in a campground on a north-facing slope of the Magaliesberg mountain range. The study area consisted of typical open savanna habitat (Branch 1998) comprising indigenous shrubs and trees, such as thorn trees (Acacia spp.), buffalo thorns (Ziziphus mucronata), common resin trees (Ozoroa paniculosa), and mountain karree (Rhus leptodictya), surrounded by low grass ground cover that was cut regularly. We mapped all 363 trees within the demarcated study area (51 $515 \mathrm{~m}^{2}$ ) and identified them to species. Each tree was numbered to facilitate mapping of tree use by lizards.

\section{Sampling of lizards}

Acanthocercus a. atricollis were caught by noosing and individually marked with colour-coded plastic collars (Insulok ${ }^{\circledR}$ cable ties). Reaney \& Whiting (2002) determined that minimum size for reproduction for females is $96 \mathrm{~mm}$ snout-vent length (SVL) and males $82 \mathrm{~mm}$ SVL. Because most $A$. $a$. atricollis were first reproductive in excess of the minimum SVL, we considered individuals with an SVL $<100 \mathrm{~mm}$ to be juveniles. Juvenile lizards were dorsally marked with a silver, permanent marker pen because tagging juveniles with collars could obviously be detrimental during growth. A total of 12 males, 20 females and 10 juveniles were marked and habitat data were obtained by locating individually marked lizards and by radio-telemetry. Owing to weight constraints, only males that exceeded $100 \mathrm{~g}(n=4)$ were fitted with a transmitter (attached to a backpack) with an external antenna and battery (Richmond 1998). Transmitters weighed $2.5 \mathrm{~g}$ and batteries weighed either 5.3 or 3.9 g. An AR8000 receiver and antenna were used to receive transmitter signals.

Lizards were located by systematically walking through the study area and scanning trees and the ground. For each identified lizard, we recorded tree number, perched height and time. Because spatial use by lizards was predictable, we sampled all individuals relatively uniformly. The number of observations for individual lizards ranged from 10-25. Lizards were located between 09:00-16:00 daily, and less often during 19:00-21:00 for night retreats. At night, we located only lizards with transmitters, using a receiver and a flashlight. We noted whether lizards were partially concealed by overhead vegetation (leaves) or if they were completely exposed.

\section{Sampling of trees}

Tree structure of 84 randomly selected trees that were not used by lizards was quantified by estimating the height of the main trunk using 2-4 $\mathrm{m}$ and $>4 \mathrm{~m}$ categories and determining the percentage in each category. Trunk diameter was determined by measuring the circumference of the main trunk $1 \mathrm{~m}$ above ground or at the main split if below $1 \mathrm{~m}$ and using the formula: circumference $=2 \pi r$, where diameter $=2 r$. The maximum canopy length and the width $90^{\circ}$ to the trunk were measured by standing under the tree and measuring the length and width of the overhead tree foliage at its maximum point. Canopy cover was determined using the formula: canopy cover $=\pi r^{2}$ $\left(\mathrm{r}=\right.$ maximum length + width $\left.90^{\circ} / 2\right) / 2$. All measurements were made to the nearest $1 \mathrm{~m}$. We also noted the presence of holes or loose bark that we considered large enough to accommodate lizards, and whether the tree was infected with a hemiparasitic plant (Viscum spp.).

\section{Statistical analysis}

A chi-square analysis was used to determine significant differences in tree species selected in relation to available trees. A $3 \times 10$ contingency table was used to detect lizard age or sex differences in tree species selected. After data for the five tree variables were square-root transformed to approximate normality, discriminant function analysis (DFA) was performed to examine the separation of groups (trees selected and not selected; lizard age and sex classes). A box modification of Bartlett's test was used to evaluate the homogeneity of variances among groups. Hole measures were left out of the multivariate analysis due to the high degree of unequal variances. We also performed MANOVA on tree physical characteristics for trees selected and not selected by lizards. We tested for significant differences between age-sex classes in diurnal perch height 
Table 1. Frequency (\%) of tree species used by Acanthocercus a. atricollis.

\begin{tabular}{lccccc}
\hline Tree species (\%) & $\begin{array}{c}\text { Total trees } \\
(n=363)\end{array}$ & $\begin{array}{c}\text { Trees selected } \\
(n=129)\end{array}$ & $\begin{array}{c}\text { Males } \\
(n=93)\end{array}$ & $\begin{array}{c}\text { Females } \\
(n=68)\end{array}$ & $\begin{array}{c}\text { Juveniles } \\
(n=18)\end{array}$ \\
\hline Sweet thorn (Acacia karroo) & 33.5 & 45.8 & 51.6 & 54.5 & 44.4 \\
Common hook-thorn (Acacia caffra) & 4.6 & 2.3 & 2.1 & 2.9 & 5.5 \\
Brack thorn (Acacia robusta) & 3.9 & 6.2 & 5.4 & 4.4 & 11.1 \\
Buffalo-thorn (Ziziphus mucronata) & 18.2 & 7 & 7.5 & 4.4 & 0 \\
Common sugarbush (Protea caffra) & 9.5 & 10.1 & 9.5 & 11.8 & 0 \\
Common resin bush (Ozoroa paniculosa) & 7.4 & 7.7 & 6.6 & 7.4 & 5.6 \\
Mountain karree (Rhus leptodictya) & 9.2 & 4.8 & 4.3 & 4.4 & 0 \\
Wild seringa (Burkea africana) & 4.6 & 4.5 & 4.3 & 3 & 5.6 \\
Dead trees & 3.3 & 8.5 & 6.5 & 4.4 & 27.8 \\
Other* & 5.8 & 3.1 & 2.2 & 2.8 & 0 \\
\hline
\end{tabular}

*Other = large-fruited bushwillow (Combretum zeyheri), live-long (Lannea discolor), Highveld cabbage tree (Cussonia paniculata), common wild pear (Dombeya rotundifolia).

using one-way ANOVA, followed by a Tukey HSD post hoc comparison of means and MannWhitney $U$ tests for adult nocturnal perch heights. All tests were two-tailed with $\alpha=0.05$. For the multiple univariate comparisons $\alpha$ levels were adjusted using sequential Bonferroni procedures to reduce Type I errors (Rice 1989). Means are reported \pm 1 S.E.

\section{RESULTS}

\section{Tree selection}

We observed Acanthocercus a. atricollis on 129 (36\%) of the 363 total number of trees in the study area. Of the trees used by A. a. atricollis, 59 (46\%) were Acacia karroo (Table 1). The proportion of tree species selected by $A$. a. atricollis did not reflect the proportion of tree species available in the study area $\left(\chi_{9}^{2}=25.52, P<0.0025\right.$; Table 1$)$. Acanthocercus a. atricollis appears to have a preference for Acacia karroo, A. robusha, and dead trees, and avoided Ziziphus mucronata and Rhus leptodictae. The species of tree selected by lizards was unrelated to lizard age or $\operatorname{sex}\left(\chi_{18}^{2}=24.10, P>0.05\right.$; Table 1$)$.

\section{Physical characteristics of trees: univariate analysis}

When tree variables where compared separately, trees used by $A$. a. atricollis had significantly larger diameter $\left(U_{129,84}=3947, P<0.001\right)$ and a higher percentage had holes $\left(\chi_{1}^{2}=7.80, P=\right.$ $0.0052)$ compared with unused trees. However, after $\alpha$ levels were adjusted, trees selected by $A$. $a$. atricollis did not have more canopy coverage $\left(U_{129,84}=4474.5, P=0.032\right)$ or parasites $\left(\chi_{1}^{2}=5.120\right.$, $P=0.024)$ and were not significantly taller $\left(\chi_{1}^{2}=\right.$ $1.12, P=0.29)$ than unused trees. When trees use by male, female and juvenile tree agamas were compared, there were no significant differences in any of the tree variables measured (height: $\chi_{2}^{2}=$ 0.450, $P>0.05$; diameter: $H_{2,179}=1.686, P=0.43$; canopy cover: $H_{2,179}=0.581, P=0.75$; holes: $\chi_{2}^{2}=5.685, P>0.05$; parasites: $\chi_{2}^{2}=0.883, P>0.05$; Table 2).

Table 2. Means ( \pm 1 S.E.) and frequency of physical characteristics of trees selected and not used by Acanthocercus a. atricollis.

\begin{tabular}{lccccc}
\hline Variable & $\begin{array}{c}\text { Trees selected } \\
(n=129)\end{array}$ & $\begin{array}{c}\text { Trees not used } \\
(n=84)\end{array}$ & $\begin{array}{c}\text { Males } \\
(n=93)\end{array}$ & $\begin{array}{c}\text { Females } \\
(n=68)\end{array}$ & $\begin{array}{c}\text { Juveniles } \\
(n=18)\end{array}$ \\
\hline Height (\%) & & & & & \\
$2-4 \mathrm{~m}$ & 20.16 & 27.38 & 17.2 & 17.65 & 11.11 \\
$>4 \mathrm{~m}$ & 79.84 & 72.62 & 82.8 & 82.35 & 88.89 \\
Diameter $(\mathrm{m})$ & $0.276(0.011)$ & $0.232(0.015)$ & $0.282(0.013)$ & $0.303(0.015)$ & $0.296(0.026)$ \\
Canopy cover $\left(\mathrm{m}^{2}\right)$ & $50.021(4.280)$ & $35.261(3.358)$ & $55.457(5.341)$ & $56.592(5.725)$ & $49.966(10.480)$ \\
Holes (\%) & 20.93 & 6 & 13.98 & 19.11 & 44.44 \\
Parasites $(\%)$ & 27.13 & 13.1 & 29.03 & 33.82 & 38.89 \\
\hline
\end{tabular}


Table 3. Loading of variables on function I from discriminant function analyses of trees selected and those not used by Acanthocercus a. atricollis based on four tree variables.

\begin{tabular}{lcc}
\hline Variables & Function & $P$-value \\
\hline Height & 0.104 & 0.710 \\
Diameter & -0.607 & 0.015 \\
Canopy cover & -0.581 & 0.034 \\
Parasites & -0.560 & 0.027 \\
Eigenvalue & 0.084 & \\
$\%$ explained & 100 & \\
\hline
\end{tabular}

\section{Physical characteristics of trees: multivariate analysis}

Variances for the three groups (trees used by male, female and juvenile lizards) were equal (Bartlett's test: $M=40.50, \chi_{30}^{2}=37.66, P=0.159$ ), however the variances for the two groups (trees selected and not selected) were unequal (Bartlett's test: $M=27.014, \chi_{10}^{2}=26.43, P=0.003$ ). The latter result indicates that the groups exhibited different patterns of variation with respect to the four variables examined. Variation in habitat variables are often analysed using MANOVA and DFA (Rienert 1984a,b). Both assume equal variances, meaning that groups respond in a similar way to the variables measured. However, this violation is often ignored due to the unrealistic nature of this assumption and the heuristic value of the test (Green 1971; Rienert 1984a,b).

An overall MANOVA for the four variables and two groups (i.e. trees selected and not selected) showed significant differences among the habitat measures $\left(\lambda=0.923, F_{4,208}=4.36, P<0.002\right.$; Table 3). Although the univariate analysis showed that selected trees only tended to have greater canopy cover and parasite infections, the DFA showed that the separation of the two groups was based significantly on diameter, canopy cover and parasite infection, but not height (Table 3). The overall MANOVA for the four habitat variables (Table 3) was not significantly different for the three age-sex groups (i.e. males, females, and juveniles) $\left(\lambda=0.979, F_{8,346}=0.460, P<0.884\right)$; similarly, the DFA failed to show any significant difference among age-sex groups in the habitat variables measured, indicating that male, female and juvenile A. a. atricollis were using similar habitats (Table 4). The multivariate analysis of trees selected by different age and sex classes therefore produced the same pattern as the univariate analysis.
Table 4. Loading of variables on functions I and II from discriminant function analyses of trees selected by male, female and juvenile Acanthocercus a. atricollis based on four tree variables.

\begin{tabular}{lrr}
\hline Variables & Function & $P$-value \\
\hline Height & 0.068 & -0.906 \\
Diameter & 1.068 & 0.144 \\
Canopy cover & -0.609 & 0.850 \\
Parasites & 0.844 & 0.169 \\
Eigenvalue & 0.014 & 0.007 \\
\% explained & 67.21 & 32.79 \\
\hline
\end{tabular}

\section{Diurnal perch heights}

Male diurnal perch height for males with transmitters $(n=4)$ versus those without $(n=8)$ was not significantly different and was therefore combined $\left(t_{10}=-0.793, P=0.446\right)$. Male $(n=12)$ perch height averaged $1.81 \mathrm{~m} \pm 0.48$, females $(n=$ 20) averaged $1.47 \mathrm{~m} \pm 0.13$ and juveniles $(n=10)$ averaged $0.92 \pm 0.19 \mathrm{~m}$. Perch height for males, females and juveniles was significantly different $\left(F_{2,39}=4.51, P=0.017\right)$. Using a Tukey HSD test, perch height for adult males and females were not significantly different $(P=0.385)$, nor were adult female and juvenile perch height $(P=0.116)$. Male perch height was, however, significantly higher than juvenile perch height $(P=0.013)$. When male, female and juvenile perch heights were combined, larger individuals had significantly higher perch heights $(r s=0.343, P=0.038$; Fig. 1$)$.

\section{Nocturnal perch heights}

Males with and without transmitters selected similar nocturnal perch heights $\left(U_{4,3}=5.5, P=\right.$ $0.860)$; these data were therefore combined. Male $(n=7)$ and female $(n=4)$ nocturnal perch height was not significantly different $\left(U_{74}=6.00, P=\right.$ $0.131)$, although females did have a lower mean

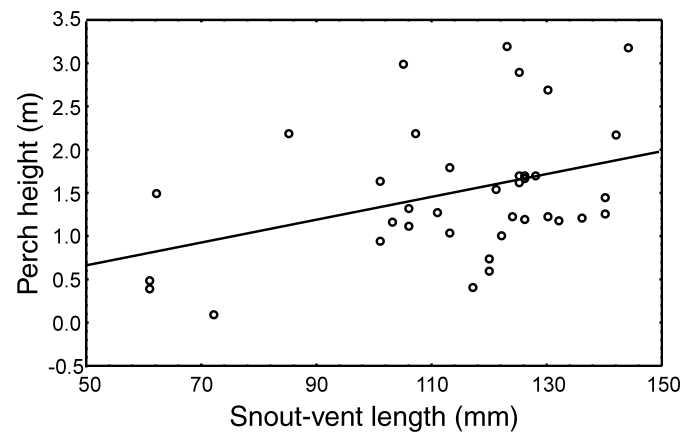

Fig. 1. Relationship between mean perch height $(\mathrm{m})$ and snout-vent length $(\mathrm{mm})$ for all age and sex classes of Acanthocercus a. atricollis. 
perch height than males (males: $3.5 \pm 0.465 \mathrm{~m}$; females: $2.3 \pm 0.358 \mathrm{~m}$ ). Both adult male and female nocturnal perch heights were higher than their diurnal perch heights (males: $U_{7,12}=8.5, P=$ 0.0046; females: $\left.U_{4,20}=14.5, P=0.048\right)$. When all night observations were combined, $A$. a. atricollis spent $67 \%$ of their time in night retreats that provided partial cover (under leaves) and 33\% totally exposed. All individuals were observed on branches and none were found in holes, although $21 \%$ of the trees selected by $A$. a. atricollis had holes large enough for occupation. We also observed two males and one female returning to their same individual nocturnal retreat sites for several nights.

\section{DISCUSSION}

Acanthocercus a. atricollis appear to be selectively occupying some tree species over others. Acacia karoo was the most commonly selected tree species, verifying anecdotal observations that $A$. $a$. atricollis are found in close association with Acacia trees (Branch 1998). Their preference for Acacia and dead trees may be explained by any number of unexamined variables including prey availability, enhanced performance in relation to crypsis and escape from predation, or some physical aspect of tree structure that enhances signaling.

We identified three physical characteristics important for tree selection by $A$. a. atricollis: tree diameter, foliage cover and the presence of holes. Acanthocercus a. atricollis' association with trees containing holes may simply be an artifact of larger/older trees containing more holes. We found no evidence that lizards were using holes as refuges or night-retreat sites. Acanthocercus. a. atricollis bury their eggs below ground, suggesting that tree holes do not serve as nesting sites. Furthermore, night-time observations showed that holes were not important retreat sites. Both adult male and female lizards were observed sleeping exposed, on branches, although often under foliage. However, Branch (1998) reported tree agamas to use hollow branches and loose bark as night-retreat sites and this tendency may vary geographically. Tree size is therefore presumably important for increasing foraging area while canopy cover could aid in crypsis.

Although tree height was not important, A. $a$. atricollis showed a preference for trees with large diameters and canopy coverage. Foliage cover is an important selection factor for arboreal lizards for the obvious benefit that it provides cover and thus reduces the likelihood of detection by predators (Cooper 1993). Acacia spp. were frequently parasitised by Viscum spp. which seems to provide extra foliage cover in early summer before leaves were abundant (pers. obs.), which may explain the lizard's association with parasitised trees. Tree size has been shown to be an important factor for habitat choice in many arboreal lizards (e.g. Eumeces laticeps, Cooper 1993; Mabuya striata, Cooper \& Whiting 2000), with individuals exhibiting strong preferences for larger trees. Acanthocercus a. atricollis' preference for trees with large diameter and canopy cover is therefore not surprising because larger trees are more complex and provide greater refuge from predators and have increased foraging surfaces and potential invertebrate prey for arboreal lizards (Cooper \& Whiting 2000).

Adult male and female tree agamas forage in a similar fashion (Reaney \& Whiting 2002), and our study failed to find any sex-related differences in habitat use. Similarly, there were no age-related differences in habitat use; both adults and juveniles occupied similar trees. However, adult males perched higher above ground than juveniles, as is the case for many other lizard taxa (reviewed in Chandler \& Tolson 1990; Clark \& Gillingham 1990). Interestingly, adults perched significantly higher above ground at night compared to during the day. Differences in diurnal versus nocturnal habitat use have been reported for several lizard taxa (e.g. Chandler \& Tolson 1990; Clark \& Gillingham 1990). Several plausible explanations exist for this relationship, the most likely of which include thermal preferences (Christian et al. 1983; Goto \& Osborne 1989), social constraints (Chandler \& Tolson 1990), and antipredatory tactics (Chandler \& Tolson 1990; Clarke \& Gillingham 1990; Vitt et al. 2002). Of these, predation pressure may be the strongest selective force driving nocturnal habitat selection in lizards. For example, Anolis trachyderma sleep higher off the ground at night and when disturbed, drop to the forest floor and remain immobile, relying on crypsis to avoid detection by predators (Vitt et al. 2002). Similarly, Puerto Rican Anolis cristatellus select short, thin branches, infrequently used by their primary predator (the boa Epicrates monensis) and sleep at the branch's extremity (Chandler \& Tolson 1990). In $A$. a. atricollis, it is unlikely that social interactions influenced perch height selection because lizards were relatively dispersed and used trees with multiple branches that would allow several lizards to occupy different parts of the same tree at 
the same height. Furthermore, adult perch height selection was not significantly different for males and females although a significant correlation existed between body size and perch height. Tree agamas are territorial (Branch 1998; pers. obs.) and it is therefore possible that some males excluded rivals from particular trees. However, we found no differences in tree selection among males, females and juveniles and any given tree species was abundant enough to exclude bias in tree selection through social interactions. Thermal influence on perch height is also questionable because trees were relatively open and therefore unlikely to have much of a thermal gradient. Furthermore, if any thermal gradient exists, temperature and tree height should be inversely related, such that lizards perching higher in a tree would experience lower temperatures. Snakes, feral cats, and various birds all feed on $A$. a. atricollis (pers. obs.). Whether selective pressures from these predators have driven nocturnal retreat site selection in $A$. $a$. atricollis remains an interesting, but unresolved problem.

\section{ACKNOWLEDGEMENTS}

We thank Owen Sutton (manager, Mountain Sanctuary Park) for accommodation and excellent support during the study, as well as his expert help with tree identification. Thanks to David Kirchhoffer, Alex Davidson, Simon Lailvaux and Andrew Muller for assistance with mapping trees and field work in general; and to Laurie Vitt and Jonathan Losos for useful references on sleeping lizards. We also thank the South African Weather Bureau for providing climatic data. This study was funded by a University Research Committee grant to M.J.W. from the University of the Witwatersrand. Clearance for this study was granted by the University of the Witwatersrand Animal Ethics Committee (clearance certificate number: 2000-86-2a). Permission to conduct the field study was granted by the North West Province Parks Board (permit number: 883/2000 NW).

\section{REFERENCES}

ANDREWS, R.A. 1971. Structural habitat and time budget of a tropical Anolis lizard. Ecology 52: 62-270.

BARTOSIEWICZ, L. 1987. Sexual dimorphism in the cranial development of Scandinavian moose. Canadian Journal of Zoology 65: 47-750.

BRANCH, B. 1998. Field Guide to Snakes and Other Reptiles of Southern Africa. Struik, Cape Town.

CHANDLER, C.R. \& TOLSON, P.J. 1990. Habitat use by a boid snake, Epicrates monensis, and its anoline prey, Anolis cristatellus. Journal of Herpetology 24: 151-157.
CHRISTIAN, K, TRACY, C.R. \& PORTER, W.P. 1983. Seasonal shifts in body temperature and use of microhabitats by Galapagos land iguanas (Conolophus pallidus). Ecology 64: 463-468.

CLARK, D.L. \& GILLINGHAM, J.C. 1990. Sleep site fidelity in two Puerto Rican lizards. Animal Behaviour 39: 1138-1148.

COOPER, W.E. 1993. Tree selection by the broad-headed skink, Eumeces laticeps: size, holes and cover. Amphibia-Reptilia 14: 285-294.

COOPER, W.E. \& WHITING, M.J. 2000. Islands in a sea of sand: use of Acacia trees by tree skinks in the Kalahari Desert. Journal of Arid Environments 44: 373-381.

GOTO, M.M. \& OSBORNE, M.A. 1989. Nocturnal microhabitats of two Puerto Rican grass lizards, Anolis pulchellus and Anolis krugi. Journal of Herpetology 23: 79-81.

GREEN, R.H. 1971. A multivariate statistical approach to the Hutchinsonian niche: bivalve molluscs of central Canada. Ecology 52: 543-556.

HEATWOLE, H. 1977. Habitat selection in reptiles. In: Biology of the Repitilia Vol. 7, (eds) C. Gans \& D. Tinkle, pp. 137-155. Academic Press, New York.

HUEY, R.B. 1982. Temperature, physiology, and ecology of reptiles. In: Biology of the Reptila Vol. 12, (eds) C. Gans \& F.H. Pough, pp. 25-91. Academic Press, New York.

JENSSEN, T.A., HOVDE, K.A. \& TANEY, K.G. 1998. Size-related habitat use by nonbreeding Anolis carolinensis lizards. Copeia 1998: 774-779.

PARTRIDGE, L. 1978. Habitat selection. In: Behavioural Ecology: An Evolutionary Approach, (eds) J.R. Krebs \& N.B. Davies, pp. 351-376. Sinauer Associates, Sunderland, Massachusetts.

PIANKA, E.R. 1986. Ecology and Natural History of Desert Lizards. Princeton University Press, New Jersey.

RAND, A.S. 1964. Ecological distribution of anoline lizards of Puerto Rico. Ecology 45: 745-752.

REANEY, L.T. \& WHITING, M.J. 2002. Life on a limb: ecology of the tree agama (Acanthocercus a. atricollis) in southern Africa. Journal of Zoology, London 257: 439-448.

REINERT, H.K. 1984a. Habitat separation between sympatric snake populations. Ecology 65: 478-486.

REINERT, H.K. 1984b. Habitat variation within sympatric snake populations. Ecology 65: 1673-1682.

RICE, W.R. 1989. Analyzing tables of statistical tests. Ecology 43: 223-225.

RICHMOND, J.Q. 1998. Backpacks for lizards: a method for attaching radio transmitters. Herpetological Review 29: 220-221.

SHINE, R. 1989. Ecological causes for the evolution of sexual dimorphism: a review of the evidence. Quarterly Review of Biology 64: 419-461.

VITT, L.J., VAN LOBEN SELS, R.C. \& OHMART, R.D. 1981. Ecological relationships among arboreal desert lizards. Ecology 62: 398-410.

VITT, L.J., AVILA-PIRES, T.C.S., ZANI, P.A. \& ESPÓSITO, M.C. 2002. Life in shade: the ecology of Anolis trachyderma (Squamata: Polychrotinae) in Amazonian Ecuador and Brazil, with comparisons to ecologically similar anoles. Copeia 2002: 275-286.

WARD, D. \& LUBIN, Y. 1993. Habitat selection and the life history of a desert spider, Stegodyphus lineatus (Eresidae). Journal of Animal Ecology 62: 353-363. 


\section{Unpublished erratum made by authors post-publication}

Picking a tree: habitat use by the tree agama, Acanthocercus atricollis atricollis, in South Africa

L.T. Reaney \& M.J. Whiting

African Zoology 38 (2): 273-278

The third column heading of Table 4 should read as follows:

Table 4. Loading of variables on functions I and II from discriminant function analyses of trees selected by male, female and juvenile Acanthocercus a. atricollis based on four tree variables.

\begin{tabular}{lcc} 
Variables & $\begin{array}{c}\text { Function } \\
\text { I }\end{array}$ & $\begin{array}{c}\text { Function } \\
\text { II }\end{array}$ \\
& & \\
\hline Height & 0.068 & -0.906 \\
Diameter & 1.068 & 0.144 \\
Canopy cover & -0.609 & 0.850 \\
Parasites & 0.844 & 0.169 \\
Eigenvalue & 0.014 & 0.007 \\
\% explained & 67.21 & 32.79 \\
& & \\
\hline
\end{tabular}

